\title{
Erratum to: Generating and using examples in the proving process
}

\author{
J. Sandefur • J. Mason • G. J. Stylianides • A. Watson
}

Published online: 13 September 2013

(C) Springer Science+Business Media Dordrecht 2013

\section{Erratum to: Educ Stud Math (2013) 83:323-340 \\ DOI 10.1007/s10649-012-9459-x}

Sandefur et al. (2013, p. 324) wrote that Iannone et al. (2011) "concluded that 'simply asking students to generate examples about a concept does not improve their abilities to write proofs about that concept...' (2011, p. 10)."

This was a misquotation. The original passage read: "To avoid misinterpretation, our studies do not imply that example generation must necessarily fail as a pedagogical technique to increase students' understandings of mathematical concepts. However, they do demonstrate that simply asking students to generate examples about a concept may not substantially improve their abilities to write proofs about that concept, at least not more so than providing students with examples to read." (Iannone et al., 2011, p.11).

The online version of the original article can be found under doi:10.1007/s10649-012-9459-x.

J. Sandefur

Georgetown University, Washington, DC, USA

J. Mason • G. J. Stylianides • A. Watson

University of Oxford, Oxford, UK

J. Mason $(\bowtie)$

Open University, Milton Keynes, UK

e-mail: jhmason27@googlemail.com 